\title{
A Mixed-Method Approach to Examining the Drivers and Outcomes of Citizen Trust Towards E-Government
}

\author{
Ahmed Saiedalameen M. Almamy, Saudi Electronic University, Saudi Arabia \\ (iD https://orcid.org/0000-0001-8915-5540 \\ Atul Mishra, Plymouth University, UK \\ Dababrata Chowdhury, University of Suffolk, UK
}

\begin{abstract}
This study investigates the antecedents and consequences of trust in e-government websites in Saudi Arabia. FSQCA and structural equation modelling were used to analyse data collected from 504 participants. The findings indicate that the unified framework possesses some predictive ability regarding citizens' intentions to use e-government services, which was superior to existing theories. The findings indicate that (1) there is no sole factor that sufficiently motivates citizens to use e-government services, (2) three distinct settings of citizens' intention drivers are probable to lead in a significant level of citizens intending to use e-government services, and (3) uncertainty avoidance has a moderating effect on citizens' intention to use e-government services. The theoretical and practical implications were demonstrated.
\end{abstract}

\section{KEYWORDS}

DOI, Intentions to Use E-Gov Services, Structural Equation Modelling and fsQCA, TAM, Trust Toward E-Gov Websites

\section{INTRODUCTION}

In Saudi Arabia (KSA), the significance of e-government (e-gov) in developing the social life and creating a knowledge-based society has been recognised by the government (YESSER, 2006, 2016), however the implemented strategies and models have been designed to fit the social life in western countries. Thus, they may not be appropriate to be applied on an eastern country such as "KSA" and ignoring the differences of the social and cultural systems (Hofstede, 2011; Hofstede et al., 2010). E-gov adoption and execution is considered a defiance to many governments in the globe (Alzahrani et al., 2017). The explanation behind that could be the wrong conviction that findings of the adoption and implementation of e-gov in a specific context could be smoothly applied in another different context. However, it is not that simple to generalise the result of such implementation by assuming a global context as each country's needs are different than the others bearing in mind its specific context. Therefore, any attempt to apply such global tactic of the adoption of e-gov in all contexts may hinder the achievement of the main goals of e-gov (Al-Hujran et al., 2015; Alomari et al., 2012). "KSA" with

\section{DOI: 10.4018/IJCRMM.289211}

This article published as an Open Access article distributed under the terms of the Creative Commons Attribution License (http://creativecommons.org/licenses/by/4.0/) which permits unrestricted use, distribution, and production in any medium, provided the author of the original work and original publication source are properly credited. 
its ambition to achieve vision of 2030 as the heart of Arab and Islamic world is energetically trying to adopt and implement e-gov services and applications in its public and private sectors institutions.

In contexts of e-commerce and the Internet, technology adoption from the customers' standpoint has been considerably studied (Agag and El-Masry, 2016a; Al-Debei et al., 2013). However, the way that trust affects e-gov success has recived less attention (Bélanger and Carter, 2008; Srivastava and Teo, 2009), wherein both Trust toward government and technology have been considered as fundamental success factors (Bélanger and Carter, 2008; Lee et al., 2011a; Srivastava and Teo, 2009). Positive users' trust of a great provision of government services will positively influence their trust to use other services provided by their government (Al-Hujran et al., 2015). In addition, positive users' trust of technology as a mean will positively enhance their trust to use online services offered by their government.

Building a good relationship with the public becomes a struggle for a lot of governments globally. Many studies' results have proven that there is a dramatic decline in the users' Trust toward their government e.g. (Alzahrani et al., 2017; Hibbing and Theiss, 2001). In fact, studies have shown that digitalised government - or e-gov - technologies can be considered as keys to enhance and build a good relationships between governments and their users (Nam, 2018; Ravishankar, 2013; Shareef et al., 2016). It has been considered as an effective tool to enhance the inner performance, the excellence's degree of service delivery and users' engagements (Dwivedi et al., 2016; Rana and Dwivedi, 2015; Rana et al., 2016). Moreover, some regard it as a powerful tool to build, improve and relief trust between users and their governments (Sandeep and Ravishankar 2014; Grimmelikhuijsen and Knies, 2017).

In e-commerce, several studies investigating users' intention to buy online have tried to test trust as an important factor that influence users' intention e.g. (Agag and El-Masry, 2016b; Flavián et al., 2006; Hsu et al., 2014; Lee and Turban, 2001). However, the contextual effect of trust toward e-gov websites in developing nations such as "KSA" has attracted scant attention (Al-Hujran et al., 2015; Chen et al., 2015) as well as if individuals' behaviour has been influenced by such trust or not. Thus, the following questions need to be answered: First, why do citizens trust e-gov websites? Second, does individuals' intention to use e-gov services is affected by their trust toward e-gov websites? By considering the lack of such integrated approach in the previous e-gov studies focusing in the contextual influence of a country such as "KSA" to investigate trust's drivers and outcomes, attempts to answers the previous questions will be presented in the current study.

Despite the important influence of national culture upon users' adoption of technology (Ashraf et al., 2014; Lee et al., 2013), its direct or moderating influence upon users' adoption of e-gov has obtained less attentions. Maximum of three countries have been sampled in those studies e.g. (Gary et al., 2015; Im et al., 2011). Moreover, the influence of various culture dimensions has not been accounted for. Subsequently, such limitation makes it difficult to generalize the findings of those studies (Takieddine and Sun, 2015; Yen et al., 2015). According to statistical evidence, $75 \%$ of customer relationship management initiatives struggle since organisations fail to assess the initiatives' cultural preparedness (Hwang and Lee, 2012). Given that uncertainty and risk are the primary constructs associated with trust beliefs, the moderating role of cultural values' uncertainty avoidance was explored in the current study model.

After conducting a review of relevant literature on e-gov adoption from the users' standpoint (e.g. Al-Refaie and Ramadna, 2017; Alzahrani et al., 2017, 2018; Kurfalı et al., 2017; Lin et al., 2011; Liu et al., 2014; Mansoori et al., 2018; Weerakkody et al., 2013), it is determined that the scope of the current models need to be widened, much attention is paid to limited factors of adoption; the theoretical frameworks are weak and not solid, and the developed models lack of generalizability (Alzahrani et al., 2018; Heeks and Bailur, 2007; Nam, 2018). Moreover, inclusive and comprehensive integration of the factors associated with the drivers of Trust toward e-gov websites has been conducted by few systematic and thorough studies (Alzahrani et al., 2018; Grimmelikhuijsen and Knies, 2017). Thus, a solid theoretical framework of the drivers and outcomes of citizens' trust toward e-gov is required. 
For this reason, this study proposes an integrated conceptual model to give a consolidated view of trust's factors that influence the use and adoption of e-gov websites.

This study embraces a distinct approach to analyse the factors that impact individuals' trust toward e-gov websites and the impact of trust on individuals' intentions to use and adopt e-gov services. Moreover, it contributes to the present literature of e-gov adoption by integrating well established theories in one model, technology acceptance model (TAM) (Davis, 1986) and Diffusion of Innovation (Rogers, 1962). Then, the proposed model is empirically tested. As far as one knows, no other studies has accomplished that. Thus, this study endeavours to contribute the following to the knowledge of e-gov context: (1) identification of the factors that decisively influence individuals' trust toward e-gov website; (2) understanding the relationship between individuals' trust and e-gov website by combining the TAM and DOI theories; (3) examining the influence of trust on individuals' intention to use e-gov services. Practically, managers of e-gov websites will benefit from the findings of the current study by developing strategies to improve the relationship between individuals' trust and e-gov websites which in turn enhance their intention to use e-gov services.

The organization of this study is structured in this way: the following section elucidates the related literature to the current study's variables, theories and the development of hypotheses. Then, a demonstration of the collected data as well as measures operationalization will be included. Thereafter an explanation of the study results, dissection, theoretical and managerial implications will be presented. Finally, limitations and future research will be demonstrated.

\section{DEVELOPMENT OF THEORETICAL FRAMEWORK}

\subsection{Technology Acceptance Model (TAM)}

This model is widely applied in studies seeking to explain user's acceptance and use of technology as well as management and information systems. Davis (1989) extended the Theory of Reasoned Action (TRA) by Fishbein and Ajzen (1975) with this model. The theory posits that individuals' actual behaviour is influenced by their intentions, which in turn is influenced by their beliefs. It includes two external psychological perceptions, namely Perceptions of ease of use (PEOU) and Perceptions of usefulness (PU) as well as the influence of attitude upon individuals' behaviour intention. Davis (1989) described (PU) as individuals' beliefs that using such technology would lead to an improvement to the job performance, whereas, (PEOU) relates to individuals' beliefs that using a specific technology would be effortless. The model is able to explain around $40 \%$ to $50 \%$ of the variance (Park, 2009).

Despite its wide usage and acceptance in the literature, unlike TRA, TAM has been criticised as it ignored important predictors such as social norms. As a response to such limitations, Venkatesh and Davis (2000) proposed a model called TAM2 incorporating subjective norms, which was found to positively influence individuals' personal image toward technology usage and explained $60 \%$ of the variance. Consequently, incorporation of TAM with other models is considered a solution by some researchers to overcome such limitations. To gain a better understanding, the substantial role played by individuals' perception of usefulness and the individuals' perception of ease of use are examined in this study.

\subsection{Diffusion of Innovation Theory (DOI)}

Diffusion of Innovation Theory is unlike the previous discussed theories, which focus on the acceptance of technology. However, DOI focuses on the dissemination of the technology, system or services. This theory proposed by Rogers (1962) is considered one of the most influential sociology models of innovation diffusion. The model is used to explain and evaluate the spread of new ideas, new technologies and innovations among users (Rogers, 2010).

According to Rogers (2003, p. 12), diffusion is "the process by which an innovation is communicated through certain channels over time among the members of a social system". Thus, 
diffusion is more concerned with the dissemination and spread of what is perceived by individuals as new. Also, he described the innovation as "an idea, practice, or object that is perceived as new by an individual or other unit of adoption" (Rogers, 2003, p. 12). Moreover, he explained the adoption decision process of an individual or the unit under analysis as one which "passes from first knowledge of an innovation to forming an attitude toward the innovation, to a decision to adopt or reject, to implementation of the new idea, and to confirmation of this decision to adopt an innovation" (Rogers, 1995, p. 21). According to Bradford and Florin (2003), all characteristics of innovation are found to be important measures of technology dissemination, except observability and trialability, as they are difficult to be measured. Therefore, this study examines the important role of relative advantages and compatibility in understanding individuals' intention to use e-gov services.

\section{RESEARCH MODEL AND HYPOTHESES DEVELOPMENT}

Despite the considerable supports have been given by previous studies to (TAM) and its ability to elucidate individuals' acceptance of information system and information technology, its ability to be used in the application and subsequent analysis of all aspects of their adoption and implementation is doubtful (Agag and El-Masry, 2016a; Lee et al., 2011b; López et al., 2008). Therefore, (TAM) merging with other theories is advised (e.g. IDT, or DeLone \& McLean's IS success model) and that will help overcoming the quick changes of IT/IS and enhance the accuracy of the produced model with a powerful explanation ability (Agag and El-Masry, 2016a; Amaro and Duarte, 2015; Carter and Bélanger, 2005; Veeramootoo et al., 2018). Regardless of the degree of similarity of some variables between TAM and IDT, but they overcome each one's limitations when integrated to investigate the adoption of IT/IS (Amaro and Duarte, 2015; Agag and El-Masry, 2016a). According to the researchers, the constructs used in TAM are fundamentally a subset of perceived innovation characteristics; consequently, combining these two theories could result in a more robust model than either theory alone (Agag and El-Masry, 2016a; Amaro and Duarte, 2015; Chen et al., 2002; Wu and Wang, 2005). Better results have been achieved by the previous studies which merged both theories together (Agag and El-Masry, 2016a; Amaro and Duarte, 2015; López et al., 2008; Sigala et al., 2000). The current study uses two predominant theoretical models (TAM) (Davis et al., 1989; Gefen, 2004; Taylor and Todd, 1995) and (IDT) (Moore and Benbasat, 1991; Rogers, 1995). Based on the revision of technology acceptance literature, main theories and empirical studies were synthesized. Subsequently, key constructs linked to individuals' acceptance of and intention of using e-gov system and services have been mingled in one model. Constructs of innovative characteristics, PEU, and usefulness, relative advantages, compatibility and intention to use e-gov, were brought and integrated from the TAM and IDT. After proper amendment, generalization of the model and findings in the context of e-gov could be accepted.

The present study seeks to fill the research gap through the integration of the TAM with the DOI Theory into a research model to fit the study of e-gov. Apart from the above-mentioned constructs, including PEOU, PU and trust are also taken into account in the proposed research model to explain citizens Trust toward e-gov website, as many studies have proven their influence on the adoption of online transactions and trust (Agag and El-Masry, 2016b; Alzahrani et al., 2018; Bélanger and Carter, 2008; Benbasat et al., 2008; Chinje and Chinomona, 2018; Elbeltagi and Agag, 2016; Gefen et al., 2003; Grimmelikhuijsen and Knies, 2017; Jafari et al., 2011; Karkin and Janssen, 2014; Teo et al., 2008; Tung et al., 2008). This research uses the theoretical foundations of the TAM and the DOI Theory to develop and test an integrated model predicting potential antecedents of Trust toward e-gov website. The hypothesized framework will be tested on e-gov.

Considering the previous revision, the proposed model including the hypothesised relations are illustrated in Fig. 1. Based on qualitative phase and previous studies in e-gov context, we chose Trust toward government, Trust toward technology, privacy/security, propensity to trust, service quality, information quality, system quality, ease of use, and relative advantages as drivers of individuals' trust 
toward e-gov websites, and consequently individuals' intentions to use e-gov services. The following section includes a discussion of the developed and proposed hypotheses.

\subsection{Trust}

Several studies have pointed out that issues related to trust, privacy and security make individuals are unwilling to adopt e-gov (Bélanger and Carter, 2008). According to Rotter (1967), trust can be described as the expected reliability of something.

\section{Figure 1. Proposed research model}

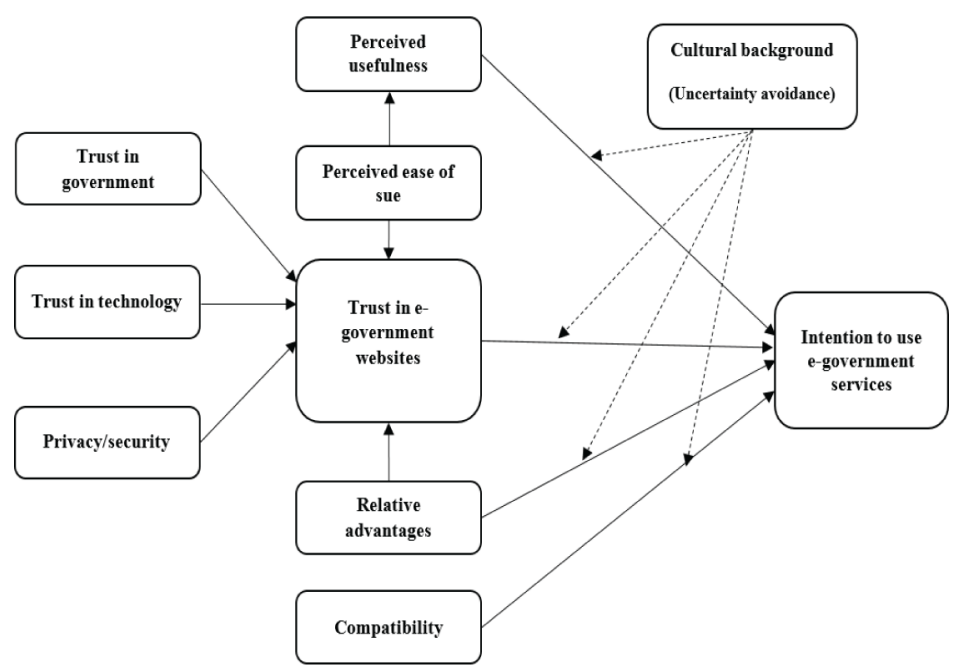

When individuals' confidence toward their government is high, their trust will also be high (Reddick and Roy, 2013), strengthen the conceptions of integrity as well as reliability (Bélanger and Carter, 2008; Benbasat et al., 2008; Lee et al., 2011a; Srivastava and Teo, 2009). Although the significant influence of trust toward technology has been considered in several e-gov studies, few have studied trust toward government as an antecedent factor (Bélanger and Carter, 2008; Jafari et al., 2011; Teo et al., 2008). The existence of individuals' trust toward e-gov websites is conditioned with existence of trust toward e-gov at the first place (Bélanger and Carter, 2008; Lee et al., 2011a; Schaupp et al., 2010; Teo et al., 2008), which will consequently lead them to trust governmental agendas (Lee et al., 2011a; Srivastava and Teo, 2009; Teo et al., 2008). Basically, individuals' readiness to embrace e-gov relays on their Trust toward technology as well as government (Beldad et al., 2012; Lee et al., 2011b; Paul and Roi, 2018; Reddick and Roy, 2013).

In the context of individuals' use of technology, several studies have employed trust as a powerful predictor to explain the perception of the users (McKnight and Chervany, 2001; McKnight et al., 2002). The use of such construct is justified by the rapid change in technology and consequently increases individuals' concerns related to privacy and security which prevent their use of e-gov (Bélanger and Carter, 2008; Benbasat et al., 2008; Lee et al., 2011a). Thus, individuals' trust toward technology is considered a valuable construct (Srivastava and Teo, 2009). For this study, Trust toward technology is simply refer to the Trust toward the means that enable services to be delivered to users (Beldad et al., 2012; Ifeonu and Ward, 2017; Weerakkody et al., 2013). Basically, to enhance individuals' trust toward e-gov websites and consequently motivate them to share information and transact, it is highly important to consider their trust toward technology at the first place. 
According to Roman (2007), the fast technological advancement have made security and privacy as primary challenges of e-commerce businesses. Precived security can be described as individuals' undrestanding of the degree of security available when they share information or transact online. Several studies findings in the context of e-commerce advocate that consumers' trust toward buying from the Internet is positivly and significanly infuluenced by individuals' perciption of privacy and security (Agag and El-Masry, 2016b; Bigné et al., 2010; Kim et al., 2011; Ponte et al., 2015; Rodríguez and Trujillo, 2014).

Previous studies of e-commerce have proven that individuals' trust and their intention to buy from the Internet are positivly related to to each other e.g. (Agag and El-Masry, 2016b; Bigné et al., 2010; Kim et al., 2011; Ponte et al., 2015; Rodríguez and Trujillo, 2014). Therefore, the subsequent hypotheses are proposed:

Hypothesis 1: Trust toward government positively influences Trust toward e-gov websites. Hypothesis 2: Trust toward technology positively influences Trust toward e-gov websites. Hypothesis 3: Privacy/Security positively influences Trust toward e-gov websites.

Hypothesis 4: Trust toward e-gov websites positively influences intention to use e-gov services.

\subsection{Relative Advantages, Compatibility, Complexity, and Intention to Use E-Gov Services}

The Perception of relative advantages of online shopping have been proven to influence individuals' intentions to buy online (Christou and Kassianidis, 2002; Kim et al., 2005; Kim and Lee, 2006; Moital et al., 2009; Wong and Law, 2005). As far as one's knows, no attention has been paid to explore the relationship between individuals' perception of relative advantage and individuals' trust. Venkatesh et al. (2003) argued that there is a similarity between (PU) in TAM and relative advantages (RA) in DOI. Shin (2010) addressed this issue of similarity and clarified the conceptual difference between the two constructs. He noted that there is an explicit inclusion of the comparison between the innovation and its precedent, whereas such comparison does not exist in the construct of perceived usefulness:

Hypothesis 5: Perception of relative advantages positively influence Trust toward e-gov websites. Hypothesis 6: Perception of relative advantages positively influence individuals' intention to use e-gov services.

Rogers (1995) described compatibility in the context of Diffusion of Innovation Theory (DOI) as individuals' perception of new technological innovation to be adopted is compatible with the values of their culture and the way they live. For a new technology or system to be disseminated within individuals or group of individuals, its compatibility must be considered as it plays a significant role (Rogers, 2003). Other studies of payment and returns from online taxes in Taiwan by Hung et al. (2006) and Wang et al. (2018) concluded that compatibility is significantly able to predict users' acceptance and according to Shareef et al. (2011), when it comes to social norms and face-to-face preference, aspects of behaviour, society, and culture all play a key role in the compatibility factor.

Hypothesis 7: Perceived compatibility positively influences individuals' intentions to use e-gov services.

\subsection{Perception of Ease of Use, Perception of Usefulness, and Intention to Use E-Gov Services}

The TAM model by Davis (1989), has been considerably utilised, academically and practically, with aim of predicting and explaining users' acceptance of information technology (IT) or its relevant 
applications (Davis, 1989; Lam et al., 2007). Here, individuals' perception of ease of use and their perception of usefulness are both prime variables that are believed to anticipate users' behavioural intentions. Davis (1989, p. 320) described individuals' perception of ease of use as the extent that the use of a system or technology is believed to be used smoothly. To the extent that this study is concerned, individuals' perception of ease of use is described as the degree that e-gov websites are believed to be used smoothly. Many studies have advocated that there is a substantially positive link between consumers' perception of ease of use and their trust (Gefen et al., 2003; Tung et al., 2008).

Indeed, theoretically and empirically, the incorporation of trust into TAM constructs has its own reinforcement (Aloudat et al., 2014; Cabanillas et al., 2014; Gefen et al., 2003; Pavlou, 2003). According to Cabanillas et al. (2014), individuals' trust is believed to be precursor of individuals' perception of ease of use, thus, having to understand, control and examine a case are reduced and consequently their mission will become easy and effortless. Different studies' findings have also proved that the perception of public values is influenced by the degree of trust. e.g. (Grimsley and Meehan, 2007; Sirdeshmukh et al., 2002).

Users' perception of usefulness and ease of use is highly supported by prior studies to be significantly and positively linked (Ayeh, 2015; Kim et al., 2008; Morosan, 2012). As per the TAM, Perceptions of usefulness is a substantial predictor of behavioural intention to use information technology. (Davis, 1989; Hart and Porter, 2004; Lee et al., 2011a), and therefore:

Hypothesis 8: Perceptions of ease of use has a positive influence on Trust toward e-gov websites.

Hypothesis 9: Perceptions of ease of use has a positive influence on perceived usefulness.

Hypothesis 10: Intention to use e-gov services will be significantly influenced by perceived usefulness.

\subsection{Cultural Background (Uncertainty Avoidance)}

Another factor that received scant consideration was cultural background. The majority of research has been conducted on North Americans. Nevertheless, the sociocultural attributes of European institutions can be examined independently of, or in contrast to, the Middle East setting (Liebenau and Smithson, 1991). Consequently, the study's applicability in other nations may be questioned (Igbaria et al., 1995).

One of the most notional elements influencing human's behaviours is culture. According to Yeniyurt and Townsend (2003), Hofstede proposed framework is believed as being the most consistence tools of measuring nations' cultural identity. Power distance, masculinity-femininity, individualism-collectivism and uncertainty avoidance are considered to distinguish one culture from another (Hofstede, 2001). It is believed that the role played by them is defining the way individuals 'expectations of services' delivery are shaped (Tsaur et al., 2005). Thus, several studies confirmed that culture dimensions with other factors have high possible influence on the way that online trade is managed (Elbeltagi and Agag, 2016; Sabiote et al., 2012).

Cultural identity, as a fountainhead of accepted standars of behaviour, might affect individuals' online preconception, their predilections, experiences as well as their attitudes in relation to e-gov. Despite that, the significant influence of culture in relation to the dissemination of e-gov is unequally dealt with, empirically and rigorously (Seng et al., 2010). Majority of those few attempts which utilized Hofstede's culture model concentrated on single or few European or American Latin countries ignoring the important of projecting those attempt globally e.g. (Akman et al., 2005; Arslan, 2009; Gouscos et al., 2007; Nam, 2018). For example, a recent study of 26 countries located in Europ indicated that national culture revealed the diversities in the rate of e-gov adoption in the targeted regions (Arslan, 2009). Arslan (2009) concluded that citezens of these regions with high power distance or high uncertainty avoidance values are less probable to use e-gov. Whereas individuals with a strong sense of individualism and/or a long-term perspective seem to be more probable to embrace e-gov than citizens of countries with a strong sense of collectivism and a short-term orientation. 
Hofstede (1993), uncertainty avoidance as the extent to which a person tend to favour structured scenarios over non - structured ones. For instance, structured scenarios are those in which there are unambiguous rules governing how someone should behave. Based on information rich theory (Daft and Lengel, 1984), consumers select media by comparing the task's information requirements to the media's information density. Consumers' needs for technology richness are greater in a highuncertainty-avoidance cultural setting. Thus, when other variables are held constant, consumers in these countries are more probable to comprehend the new technological advancement as less helpful. Consequently, consumers would prefer to use a channel that contains more information in the same situations. Moreover, consumers in high uncertainty avoidance depends on others' opinion to decrease the uncertainty:

Hypothesis 11: Perceptions of usefulness has less influence on intention to use e-gov services for citizens in a high uncertainty avoidance culture.

Hypothesis 12: Trust toward e-gov websites has more influence on intention to use e-gov services for citizens in a high uncertainty avoidance culture.

Hypothesis 13: Relative advantages have less influence on intention to use e-gov services for citizens in a high uncertainty avoidance culture.

Hypothesis 14: Compatibility has less influence on intention to use e-gov services for citizens in a high uncertainty avoidance culture.

\section{METHODOLOGY}

The present study utilized a mixed-method includes a qualitative technique preceded by a quantitative technique of data gathering and analysis to expand on the preliminary findings (Tashakkori \& Teddlie, 2003). The qualitative technique was utilized to supplement the inconclusive and incoherent findings from preceding studies. The adoption of qualitative phase assists to explore the main variables affecting citizen trust toward e-gov. This exploratory study leads to building a conceptual framework to be tested in the quantitative technique.

\subsection{Qualitative Phase}

The qualitative phase utilised semi-structured interviews in order to gather qualitative information. The paucity of qualitative methods into the Trust toward e-gov context and the incomplete prior studies results motivated us to utilize a qualitative technique to explore factors affecting citizens' trust toward e-gov. A market research firm assists us to conduct a qualitative study including 15 oneto-one, probed deeply interviews (45-minute duration for each) throughout a five-day period in June 2018 in Riyadh. Upon the consent of the participants, all interviews were recorded.

Respondents were questioned about their experience and knowledge with e-gov websites, as well as the critical factors affecting their Trust toward these sites. The researcher elicited general responses about respondents' experiences (e.g., their thoughts and opinions of the website's content, their preferences, and their satisfaction with the website's content), as well as specific responses about website content, layout, and navigation) that cover serval issues such as privacy, information quality, trust, and security. Respondents were questioned to mark words in the questions that they found vague or perplexing and to make general observations about the statements.

The data were analysed and themes deduced based on the authors' knowledge of the topics and the meaning conveyed in the content (Ryan \& Bernard, 2003). Two authors verified independently the identified factors list for accuracy. The analysis results demonstrate that variables identified in prior studies, such as Trust toward government, Trust toward technology, relative advantages, ease of use, privacy, security, and compatibility appeared to be driving citizen trust toward e-gov, while propensity to trust, service quality, information quality, and system quality, which had not been 
investigated previously, were newly discovered to be critical components of e-gov trust. As illustrated in Figure 2, the qualitative findings and findings from previous studies have been combined to create an integrated model of the factors affecting citizens' Trust toward e-gov websites.

Figure 2. Final research model

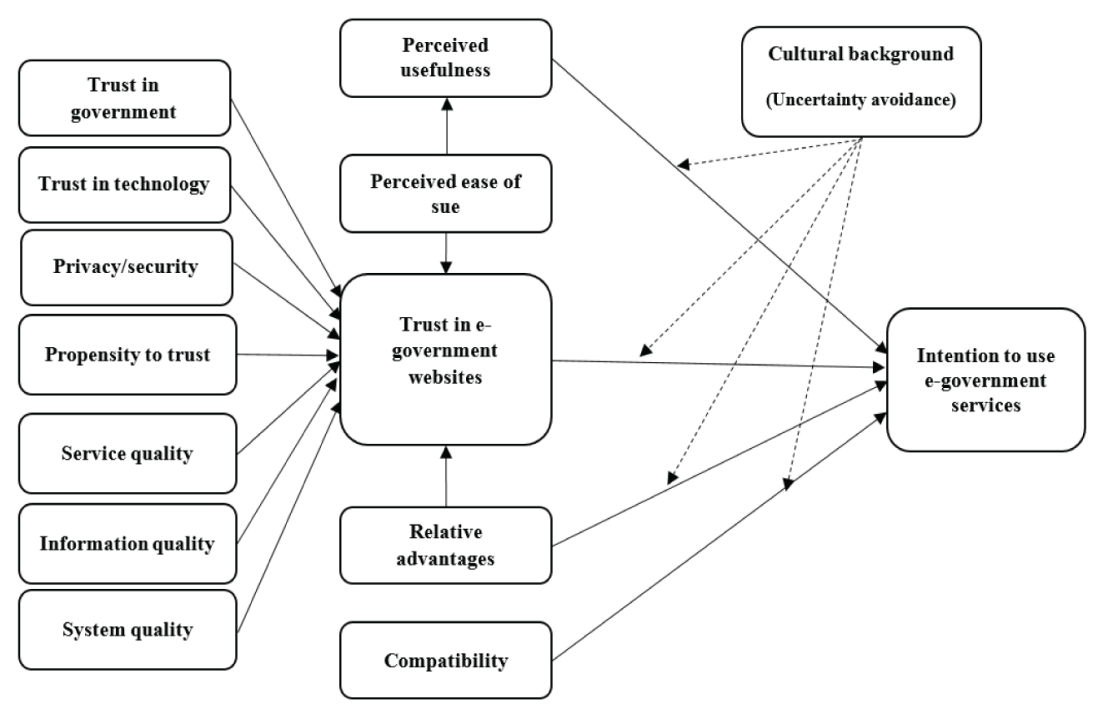

\subsection{Quantitative Method}

\subsubsection{Instrument and Data Collection}

A quantitative collection of the users' data was applied by utilizing questionnaires to approach different level of the research.

Based on the prior literature, the design of the questionnaire characterised with self-completion and well-structured. The sample was randomly selected, and the users voluntarily participated to answer the questionnaires. There is an emphasis by Sekaran (2003) regarding the crucial role of selecting questioners' language that is able fit the variations of participants' understanding. Since Arabic is the spoken language of "KSA" citizens, translation of the questionnaire from English to Arabic has been done by utilizing two independent and experienced translators. Two Phases of translation have been adopted. The first phase was English to Arabic which has been done by one translation. The second phase was Arabic to English which has been done by another translator.

Having followed ethical clearance by the University's human ethics review committee, 4,000 potential respondents' e-mail lists were procured from a trusted "KSA" market list company. Prospective panellists were encouraged to join through the use of a sequence of mailings in each of English and Arabic, as well as a phone call follow-up to those who did not respond. This marketing company possessed a repository of over 3 million approved customer at the time of this research. Members were chosen to participate in this research questionnaire employing a probability weighted sampling strategy proportional to size and were provided with e-mail lists, devices, and the internet was accessible. However, considering the ubiquity of electronic communications in today's world, facilitated access was little required. The early e-mails were sent to 3,000 randomly selected respondents participant employing probability sampling techniques (consumers' e-mail lists were randomly selected using a generated sampling mechanism, such as random-digit-dialling (RDD)). Additionally, the e-mail 
request included information about the study's purpose, the estimated time required to complete the survey, and the URL web address to the survey. In July 2018, data gathering lasted nearly four weeks. A sum of 930 participants answered the questionnaires during this time period. Due to some items were not answered, 37 questionnaires were useless. A sum of 893 questionnaires were analysed. Out of 893 questionnaires, 504 (56.5\%) participants had adopted and used e-gov services, whereas $43.5 \%$ of the participant had not. This suggests that they answered the questionnaires based on their background information. Therefore, to validate and test the proposed hypotheses, 504 participants were considered a valid sample as they had used and adopted e-gov services.

\subsection{Measurement Scales}

The survey of the current study was split into two partitions. The first section included queries designed to assess constructs using pre-existing metrics or closely related scales.

The scale used to measure Trust toward technology, Trust toward government and Trust toward e-gov websites was the same to a scale used in prior works (Bélanger and Carter, 2008; McKnight et al., 2002; Teo et al., 2008; Wang and Benbasat, 2008) and revised in light of a pilot study. The scale of privacy/security was created using previous related researches (Kim et al., 2008; Ponte et al., 2015). From the literature, system quality, information quality, service quality, and propensity to trust came from Urbach et al (2010) and Gefen and Straub (2004). As recommended by Castañeda et al. (2007), Davis (1989) and Moore and Benbasat (1991), four items were operationalised for each of Perceptions of ease of use, perception of usefulness. The utilised scale to measure relative advantages and compatibility was adopted from prior studies of online context (Carter and Bélanger, 2005; Davis, 1989; Moore and Benbasat, 1991; Pavlou, 2003). Intention to use e-gov services was adapted from Venkatesh and Davis (2000). Uncertainty avoidance was adapted from Venkatesh and Davis (2000) and Bigné et al. (2010).

Structural equation modelling (SEM) were utilised instead of basic regression once due to its power of testing a sequence of dependence associations at the same time (Hair, 2013). For the validation and testing the adopted measurements and proposed hypotheses, Partial Least Squares or (PLS-SEM) were employed and WarpPLS software was utilised. The reasons behind such use of PLS are that it minimises the dependent variables' residual variances as well as it is a proper tool to analyse many paths simultaneously (Hair, 2013). In addition, PLS is not limited to the criteria of normally distributed data, whereas covariance based is limited to this criteria (Jörg et al., 2012). Lastly, to test sophisticated models (e.g., many paths, multiple mediators), PLS is advised to be used (Magnusson et al., 2013).

\subsection{Sample Profile}

The descriptive statistics of the analysed data concluded that $57.0 \%$ of the participants were male and $43.0 \%$ were female. Participants ranged between 20 and 30 years old are the dominant group which represented 56.0\%. Most of participants were undergraduates (i.e. bachelor) either in business related course or IT related course and embodied $69.0 \%$ of the total. The majority of the participants' Internet experiences $(47.0 \%)$ were below 3 years and they use the Internet persistently. Even thought, lack of participants' e-commerce experiences was obvious as they disclosed. Moreover, the access and use of e-gov were infrequent compared to the common Internet tasks. The findings are illustrated in Table 1.

\section{DATA ANALYSIS AND RESULTS}

The current study utilises the Structural Equation Modelling (SEM) approach with Partial Least Squares (PLS) as a tool to analyse data. It is a commonly utilised tool to test and validate theories. The examining of psychometric properties by PLS helps finding either links between constructs are presented or not with proper evidences (Fornell and Larcker, 1981). By employing WarpPLS, twostages methodology was performed to analyze data (Anderson and Gerbing, 1988). Firstly, content, 
Table 1. Sample Profile

\begin{tabular}{|l|l|l|l|}
\hline & & Frequency & Percentage (\%) \\
\hline Gender & Male & 287 & 57 \\
& Female & 217 & 43 \\
\hline Age & Less than 20 & 66 & 13.0 \\
& $20-30$ & 282 & 56.0 \\
& $3-40$ & 116 & 23.0 \\
& $41-50$ & 40 & 8.0 \\
& over 50 & - & - \\
\hline Education & Bachelor & 348 & 69.0 \\
& Postgraduate & 156 & 31.0 \\
\hline Internet experience & Other & - & - \\
& $<3$ times & 237 & 47.0 \\
& $3-6$ times & 161 & 32.0 \\
& $6-9$ times & 91 & 18.0 \\
& $>9$ times & 15 & 3.0 \\
\hline
\end{tabular}

convergent and discriminant validity of constructs were evaluated employing the measurement model. Secondly, the structural model and hypotheses were tested.

\subsection{Measurement Model}

To establish content validity for the current study questionnaire instrument, two methods were performed. Firstly, the validation of the constructs and the constructs' measures was performed. In this case, all the employed construct with their measures were used from current literature and the content validation has been previously performed in prior studies.

Secondly, beside the domain experts, the pretest was undertaken, and the findings confirmed the content of the questionnaire instrument was valid. To examine whether the scale is reliable or not, a widely employed approach to examine reliability and internal consistency is known as Cronbach's alpha was utilized (Cronbach, 1970). It is recommended that its value for all constructs individually to be equal or above 0.70 for a scale to be reliable (Hair, 2006). For the current study, all the model's constructs show Cronbach's alpha results that range between the acceptable value of 0.7 to 0.89 . This indicates that internal consistency is highly presented. The results are illustrated in Table 2.

To examine the convergent validity in the model, two measures were tested. Firstly, composite reliability (CR) test was performed to check that each construct result is equal or higher than 0.7 based on Fornell and Larcker (1981) suggestion. Secondly, Average Variance Exacted (AVE) test was performed to check that constructs' values are equal or above 0.5 based on Fornell and Larcker (1981) suggestion. As a result, both previous tests' values were higher than the accepted levels. In addition, the standardised loadings of paths for all indicators were higher than 0.55 . Therefore, all the loadings were significantly accepted (Falk and Miller, 1992). According to the all previous tests, content validity, reliability and convergent validity satisfied the criteria for the current study.

To establish discriminant validity, the shared correlation of the construct and other constructs in the proposed model should be lower than the square root of the Average Variance Extracted (AVE) from the construct based on Chin (1998) suggestion. For the current study, the previous condition was proved. The results are shown in Table 2, 3 and 4).

To inspect for common method bias, we conducted a Harman's single factor test (Podsakoff and Organ, 1986). An exploratory factor analysis was conducted, entering all the items for the latent variables of this survey. The largest factor explained 28.27 percent of the variance (the variances presented varied from 16.32 to 28.27 percent), and no single variable presented more than 50 percent of the variance. Non-response bias was also checked according to the approach followed by Armstrong 
and Overton (1977) who suggested that substantial variations between early and late participants should not be existed. The early stage includes 250 participants who completed the survey; while the late stage includes 200 participants completed the survey. We conducted chi-square test and the results of the test did not show any substantial variations among early and late participants at 0.05 significance level. Consequently, the issue regarding non-response bias was excluded.

\subsection{Structural Model Assessment}

The model explains $69 \%$ of the variance for intention to use e-gov services, $57 \%$ of the variance for Trust toward e-gov websites, and $34 \%$ of the variance for perceived usefulness. To test $\mathrm{H} 1-\mathrm{H} 10$, test to the inner model was performed in Fig. 3. The global fit values were satisfied, APC $=(0.174$, $\mathrm{p}<0.001), \mathrm{ARS}=(0.741, \mathrm{p}<0.001), \mathrm{AARS}=(0.710, \mathrm{p}<0.001), \mathrm{AVIF}=(2.817)$ and $\mathrm{GOF}=(0.753)$. With an exception to hypotheses 11, model's hypothesised relationships are confirmed.

According to the results, the most powerful predictors of intention to use e-gov services were; Trust toward e-gov websites $(\beta=0.63, \mathrm{P}<0.001)$, relative advantages $(\beta=0.23, \mathrm{P}<0.001)$, and compatibility $(\beta=0.33, \mathrm{P}<0.001)$. Contrary to our predictions, Perceptions of usefulness $(\beta=$ $0.09, \mathrm{P}<$ insignificant) has no powerful prediction ability (insignificant) in their relationship with (intention to use e-gov services).

Results also indicate that ease of use significantly predicts Perceptions of usefulness $(\beta=0.53$, $\mathrm{P}<0.001)$ and Trust toward e-gov websites $(\beta=0.41, \mathrm{P}<0.001)$. Finally, the influence of Trust toward government, Trust toward technology and perceived privacy/security, propensity to trust, service quality, information quality, and system quality on Trust toward e-gov websites is proved to be powerful and significantly high.

According to Ahuja and Thatcher (2005) and Chang et al. (2014), T-statistics was produced. As illustrated in Table. 5, Perceptions of usefulness and relative advantages exert stronger influence on intention to use e-gov services for citizens with lower levels of uncertainty avoidance, while, Trust toward e-gov websites exert stronger influence on intention to use e-gov services for citizens with higher levels of uncertainty avoidance, indicating H12, H13, H14 are supported.

\subsection{A Configuration View Utilising Fuzzy-Set Qualitative Comparative Analysis (fsQCA)}

As illustrated in Table 3, the estimated correlation coefficients for several variables are higher than 0.60 . This implies that the linkages between model variables and the intention to use e-gov services may be asymmetric; thus, the same result could have been derived from a variety of different causal conditions (Pappas \& Papatheodorou, 2017). As a result, this study employs a configuration mechanism via fsQCA to gain a thorough view of the factors influencing citizens' intention to use e-gov services. Utilising set theory, the fsQCA approach investigates how causal conditions as configurations relate to the desired outcome (Fiss, 2011). The fsQCA technique was utalised to analyse the data and enable the determination of what conditions contribute to citizens' use of e-gov services. The data were modified using the fsQCA technique (Ragin \& Davey, 2014) to suit the membership magnitude of cases in sets, with values ranged from 0.0 to 1.0 , in order to convert the conventional factors to fuzzy sets (Ragin et al., 2008).

In the current study a combination of Trust toward e-gov drivers, perceived usefulness, relative advantages, and compatibility were hypothesized as the causal conditions that impact citizens' intention to use e-gov services. The fsQCA procedure can be used to determine the effect of various variables on citizens' intentions to use e-gov services. Nevertheless, it is difficult for government to continue pursuing a higher level of performance from each driver to enable the realization of higher citizens' intention to use e-gov services. Numerous mixtures of these variables should be examined to determine what other combinations result in an increase in citizens' intention to use e-gov services. Therefore, the fsQCA technique aims to investigate various combinations of variables that take place between comparable cases and lead to a greater citizens' intention to use e-gov services. 
Table 2. Measurement's statistics of constructs scales

\begin{tabular}{|c|c|c|c|c|}
\hline Construct indicators & Indicator loadings & $\begin{array}{l}\text { Composite } \\
\text { reliability }\end{array}$ & $\begin{array}{c}\text { Cronbach's } \\
\text { alpha }\end{array}$ & $\begin{array}{l}\text { Average variance } \\
\text { extracted (AVE) }\end{array}$ \\
\hline $\begin{array}{l}\text { Intention to use e-gov services } \\
\text { IN1 } \\
\text { IN2 } \\
\text { IN3 } \\
\text { IN4 }\end{array}$ & $\begin{array}{l}0.97 \\
0.90 \\
0.91 \\
0.85\end{array}$ & 0.93 & 0.91 & 0.68 \\
\hline $\begin{array}{l}\text { Trust toward Government } \\
\text { TG1 } \\
\text { TG2 } \\
\text { TG3 } \\
\text { TG4 }\end{array}$ & $\begin{array}{l}0.92 \\
0.87 \\
0.91 \\
0.88\end{array}$ & 0.89 & 0.86 & 0.72 \\
\hline $\begin{array}{l}\text { Trust toward Technology } \\
\text { TT1 } \\
\text { TT2 } \\
\text { TT3 }\end{array}$ & $\begin{array}{l}0.98 \\
0.95 \\
0.89\end{array}$ & 0.95 & 0.92 & 0.62 \\
\hline $\begin{array}{l}\text { Privacy/Security } \\
\text { PS1 } \\
\text { PS2 } \\
\text { PS3 } \\
\text { PS4 }\end{array}$ & $\begin{array}{l}0.86 \\
0.92 \\
0.96 \\
0.92\end{array}$ & 0.92 & 0.88 & 0.69 \\
\hline $\begin{array}{l}\text { Propensity to trust } \\
\text { PRT1 } \\
\text { PRT2 } \\
\text { PRT3 }\end{array}$ & $\begin{array}{l}0.89 \\
0.93 \\
0.91\end{array}$ & 0.93 & 0.91 & 0.57 \\
\hline $\begin{array}{l}\text { Service quality } \\
\text { SRQ1 } \\
\text { SRQ2 } \\
\text { SRQ3 } \\
\text { SRQ4 }\end{array}$ & $\begin{array}{l}0.89 \\
0.93 \\
0.88 \\
0.90\end{array}$ & 0.94 & 0.92 & 0.54 \\
\hline $\begin{array}{l}\text { Information quality } \\
\text { IRQ1 } \\
\text { IRQ2 } \\
\text { IRQ3 } \\
\text { IRQ4 }\end{array}$ & $\begin{array}{l}0.95 \\
0.93 \\
0.90 \\
0.91\end{array}$ & 0.92 & 0.89 & 0.62 \\
\hline $\begin{array}{l}\text { System quality } \\
\text { SYQ1 } \\
\text { SYQ2 } \\
\text { SYQ3 } \\
\text { SYQ4 }\end{array}$ & $\begin{array}{l}0.89 \\
0.87 \\
0.90 \\
0.93\end{array}$ & 0.93 & 0.90 & 0.64 \\
\hline $\begin{array}{l}\text { Trust toward Website } \\
\text { TW1 } \\
\text { TW2 } \\
\text { TW3 }\end{array}$ & $\begin{array}{l}0.98 \\
0.94 \\
0.92\end{array}$ & 0.94 & 0.90 & 0.72 \\
\hline $\begin{array}{l}\text { Ease of Use } \\
\text { EU1 } \\
\text { EU2 } \\
\text { EU3 } \\
\text { EU4 }\end{array}$ & $\begin{array}{l}0.95 \\
0.97 \\
0.88 \\
0.92\end{array}$ & 0.96 & 0.89 & 0.69 \\
\hline $\begin{array}{l}\text { Usefulness } \\
\text { US1 } \\
\text { US2 } \\
\text { US3 } \\
\text { US4 }\end{array}$ & $\begin{array}{l}0.98 \\
0.86 \\
0.98 \\
0.94\end{array}$ & 0.95 & 0.94 & 0.58 \\
\hline
\end{tabular}


Table 2. Continued

\begin{tabular}{|l|l|l|l|l|}
\hline \multicolumn{1}{|c|}{ Construct indicators } & Indicator loadings & \multicolumn{1}{|c|}{$\begin{array}{c}\text { Composite } \\
\text { reliability }\end{array}$} & $\begin{array}{c}\text { Cronbach's } \\
\text { alpha }\end{array}$ & $\begin{array}{c}\text { Average variance } \\
\text { extracted (AVE) }\end{array}$ \\
\hline Relative Advantages & 0.96 & 0.96 & 0.93 & 0.78 \\
RA1 & 0.93 & & & \\
RA2 & 0.87 & & & \\
RA3 & 0.89 & 0.95 & 0.90 & \\
RA4 & 0.98 & & & \\
\hline Compatibility & 0.95 & & & \\
CM1 & 0.93 & 0.68 & \\
CM2 & 0.87 & 0.88 & 0.83 & \\
CM3 & & & & \\
\hline Uncertainty Avoidance & 0.90 & 0.93 & & \\
UN1 & 0.89 & & & \\
UN2 & & & \\
UN3 & & & & \\
\hline
\end{tabular}

Notes: IN= Intention to Use e-gov Services; TG= Trust toward Government; TT= Trust toward Technology; PS= Privacy/Security; PRT= Propensity to trust; $S R Q=S e r v i c e$ quality; IRQ= Information quality; SYQ= System quality; TW= Trust toward Website; EU= Perception of Ease of Use; US= Perception of Usefulness; RA= Relative Advantages; $\mathrm{CM}=$ Compatibility; UN= Uncertainty Avoidance.

Table 3. Convergent/discriminant validity testing results

\begin{tabular}{|c|c|c|c|c|c|c|c|c|c|c|c|c|c|c|}
\hline \multirow[t]{2}{*}{ Construet } & & & & & & \multicolumn{9}{|c|}{ Correlations and square roots of AVE } \\
\hline & DV & IG & TT & PS & PRT & SRQ & $\mathbb{R} Q$ & SYQ & TW & EU & tS & RA & CMI & LNC \\
\hline IN & (0.824) & & & & & & & & & & & & & \\
\hline TG & 0.590 & $(0.848)$ & & & & & & & & & & & & \\
\hline IT & 0311 & 0.448 & $(0.787)$ & & & & & & & & & & & \\
\hline PS & 0.278 & 0.348 & 0.521 & (0.830) & & & & & & & & & & \\
\hline PRT & 0.502 & 0.219 & 0.302 & 0.128 & $(0.755)$ & & & & & & & & & \\
\hline SRQ & 0.427 & 0.219 & 0.127 & 0.417 & 0.236 & $(0.735)$ & & & & & & & & \\
\hline IRQ & 0.412 & 0.317 & 0.328 & 0.402 & 0.218 & 0.392 & $(0.721)$ & & & & & & & \\
\hline SYQ & 02800 & 0.219 & 0.502 & 0.289 & 0,329 & 0.209 & 0.473 & $(0.801)$ & & & & & & \\
\hline TW & 0.128 & 0.439 & 0.432 & 0237 & 0.387 & 0.632 & 0.290 & 0.394 & $(0.849)$ & & & & & \\
\hline $\mathbf{E U}$ & 038 & 0.271 & 0.128 & 0.418 & 0.132 & 0.437 & 0.538 & 0.550 & 0.218 & (0.831) & & & & \\
\hline US & 0520 & 0.521 & 0.329 & 0.420 & 0.293 & 0.278 & 0.239 & 0.532 & 0.490 & 0.636 & $(0.762)$ & & & \\
\hline RA & 0.402 & 0.430 & 0.319 & 0572 & 0.471 & 0.387 & 0.420 & 0.639 & 0375 & 0.298 & 0.432 & $(0.884)$ & & \\
\hline CM & 0520 & 0376 & 0219 & 0210 & 0.519 & 0.128 & 0.427 & 0.519 & 0230 & 0247 & 0532 & 0.228 & (0.824) & \\
\hline $\mathrm{UNC}$ & 0320 & 012 & 0.127 & 0.278 & 0.273 & 0.437 & 0.384 & 0.338 & 0.238 & 0.428 & 0.348 & 0.487 & 0.437 & $(0.866)$ \\
\hline
\end{tabular}

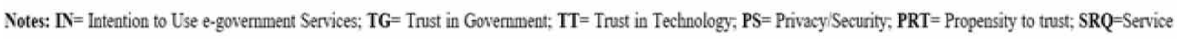
quality; IRQ= Information quality; $\mathbf{S Y Q}=$ System quality; $\mathbf{T W}=$ Trust in Website; $\mathbf{E U}=$ Perceived Ease of Use; $\mathbf{U S}=$ Perceived Usefulness; RA= Relative Advantages; $\mathbf{C M =}$ Compatibility; $\mathbf{U N}=$ Uncertainty Avoidance. 


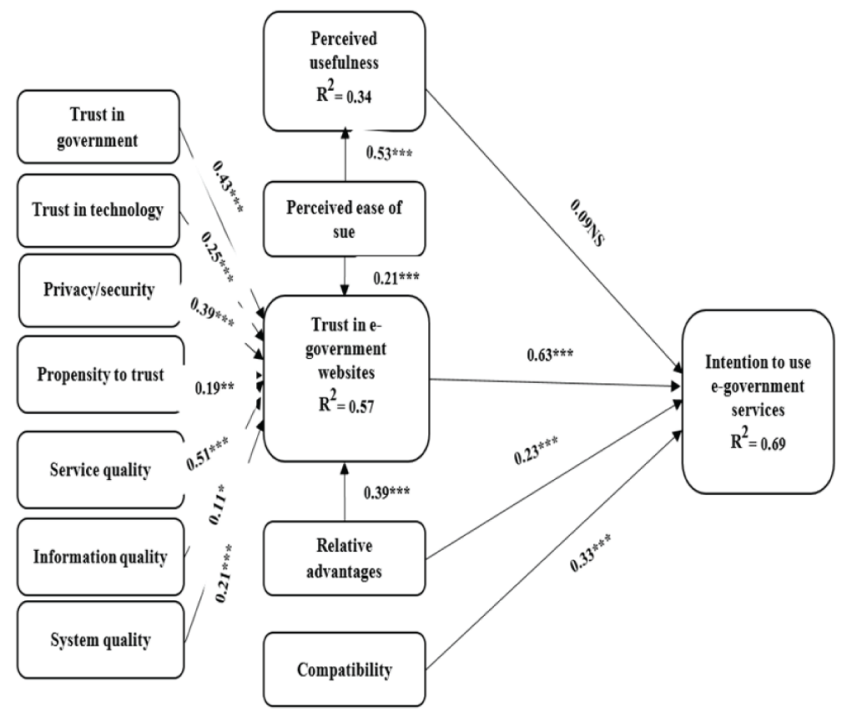

\subsection{Results}

The outcomes of the fsQCA analysis for a high level of citizen intention to use e-gov services (intermediate solution with consumer intention) are shown in Table 5. The dark symbols "O" denote the existence of a causal condition, the light symbols " $\bigcirc$ " denote the exclusion or denial of a condition and the blank field denote "does not matter" condition. Table 5 contains the raw coverage and consistency metrics for every solution. This demonstrates to what extant citizens' intention to use e-gov services is determined by the identified configurations of Trust toward e-gov drivers, perceived usefulness, relative advantages, and compatibility.

According to the findings in Table 5, no single variable will result in a significant chances of using e-gov services, but combinations of variables will result to greater chances of using e-gov services. Particularly, the findings indicated that three solutions with high raw consistency (higher than 0.90 ) were associated with a high intention of using e-gov services.

Solution 1 suggests that the presence of Trust toward government, Trust toward technology, system quality, service quality, Trust toward websites, ease of use, relative advantages and low privacy/ security and information quality will lead to high citizens' intention to use e-gov services even in the absence of propensity to trust, compatibility, and Perceptions of usefulness as it shows a consistency score of 0.96 . This combination is possessed by $85 \%$ of the citizens (raw coverage). As a substitute, combination 2 indicates that the existence of Trust toward government, Trust toward technology, service quality, Trust toward websites, Perceptions of usefulness and low system quality, ease of use, and compatibility will result in high citizens' intention to use e-gov services even in the absence of privacy/security, propensity to trust, information quality, and relative advantages as it shows a consistency score of 0.94 . This combination is possessed by $68 \%$ of the citizens (raw coverage). In addition, solution 3 demonstrates that the presence of Trust toward government, service quality, Trust toward websites, ease of use, and low Trust toward technology, privacy/security/ propensity to trust, perceived usefulness, and compatibility will result in high citizens' intention to use e-gov services even in the absence of information quality, system quality, and relative advantages as it demonstrates a consistency score of 0.91 . This combination is possessed by $39 \%$ of the citizens (raw coverage). Table 5 demonstrates that all consistency values are at least 0.95 , showing that these configurations are sufficient conditions causing high citizens' intention to use e-gov services. Solution coverage is 
Table 4. Statistical comparison of paths

\begin{tabular}{|c|c|c|c|c|c|}
\hline \multirow[b]{2}{*}{ Paths } & \multicolumn{2}{|c|}{ h uncertainty avoidance $(\mathbf{R} 2=0.31)$} & \multicolumn{2}{|c|}{ Low uncertainty avoidance $(R 2=0.64)$} & \multirow[t]{2}{*}{ Statistical comparison paths } \\
\hline & tandardize & t t-value & standardize & nt t-value & \\
\hline $\mathrm{UF} \longrightarrow \mathrm{INT}$ & 0.05 & 1.74 & 0.31 & 4.390 & $5.493^{* * *}$ \\
\hline TW $\longrightarrow$ INT & 0.43 & 5.743 & 0.13 & 2.407 & $6.430^{* * *}$ \\
\hline $\mathrm{RA} \longrightarrow \mathrm{INT}$ & 0.02 & 1.49 & 0.21 & 5.420 & $5.120^{* * *}$ \\
\hline $\mathrm{CM} \longrightarrow \mathrm{INT}$ & 0.04 & 3.21 & 0.07 & 2.734 & $3.403 \mathrm{NS}$ \\
\hline
\end{tabular}

Table 5. Intermediate solution with intention to use e-government services as the casual outcome

\begin{tabular}{|c|c|c|c|c|c|c|c|c|c|c|c|c|c|c|}
\hline Solution & TG & TT & PS & PRT & SRQ & IRQ & SYQ & TW & EU & US & RA & \multicolumn{3}{|c|}{ Coverage } \\
\hline 1 & $\bullet$ & $\bullet$ & 0 & & $\bullet$ & 0 & $\bullet$ & $\bullet$ & $\bullet$ & & $\bullet$ & & 0.85 & 0.96 \\
\hline 2 & $\bullet$ & - & & & • & & 0 & • & 0 & $\bullet$ & & 0 & 0.68 & 0.94 \\
\hline 3 & $\bullet$ & 0 & 0 & 0 & • & & & $\bullet$ & $\bullet$ & 0 & & 0 & 0.39 & 0.91 \\
\hline Notes: & & & & & & & & & & & & & & \\
\hline
\end{tabular}

greater than 0.8 , which suggests that the solution explains a large proportion of citizens' intention to use e-gov services.

\section{DISCUSSION AND CONCLUSION}

\subsection{Discussion of Findings}

Using a dual PLS-SEM and fsQCA technique, the current study attempts to investigate the drivers and outcomes of citizens' intentions to use e-gov services in "KSA" context. Findings from consumers $(n=504)$ indicated that none of the factors is sufficient to drive citizens' intentions to use e-gov services and three distinct configurations of citizens' intentions to use e-gov drivers are likely to lead in great citizens' intentions to use e-gov services.

Proposing and empirically testing an inclusive model representing the factors affecting consumers' trust towards e-gov websites and its influences on consumers' intentions to use e-gov services were the main purposes of the current study. Eight constructs are modelled to build consumers' trust towards e-gov websites: Trust toward technology, Trust toward government, privacy-security, propensity to trust, service quality, information quality, system quality, ease of use and relative advantages. Intentions to use e-gov services represents consequences of website trust. Information of e-gov websites' users $(n=504)$ has concluded that Trust toward technology, Trust toward government, privacy/security, 
propensity to trust, service quality, information quality, system quality, ease of use and relative advantages are considered fundamental indicators to build a trustworthy website. Trust is a primary benchmark for e-gov services, as it is affect the intention to use e-gov services.

With regard to the antecedents of e-gov website trust, the findings of Structural Equation Modelling indicate that Trust toward technology, Trust toward government, privacy-security, propensity to trust, service quality, information quality, system quality, ease of use and relative advantages have significant influence on trustworthiness of a website. The results spotlight a positive link which is in line with prior researches' findings (e.g. Agag and El-Masry, 2016a; Bhandari and Rodgers, 2018; Beldad et al., 2012; Tam and Oliveira, 2017; Alzahrani et al., 2017; Bigné et al., 2010; Kim et al., 2011; Ponte et al., 2015; Rodríguez and Trujillo, 2014; Warkentin et al., 2018).

The findings also conclude that the perception of ease of use and the perception of usefulness are both pertinent precursors in forming a website's trustworthiness. Thus, the TAM remains valid for "KSA" (i.e., high cultural dimensions' values). An apprehension has been indicated in the previous studies that the application of TAM in the context of a country with high cultural dimension values. However, the study's findings uncovered salutary insights with respect to the suitability and generalisability of the TAM Model in a culture characterised with high cultural dimension values such as "uncertainty avoidance", "power distance" and "masculinity" (McCoy et al., 2007; Straub et al., 1997). The findings of the present study are in line with Adams et al. (1992), who have indicated this a substantial role is played by PEOU in the initial adoption levels.

The results also show that Perceptions of usefulnesshad no discernible effect on the intention to use e-gov services. One likely interpretation behind it is that The "KSA" citizens are probable to be highly concerned about their capability and skills in using the website than the e-gov services benefits once deciding to adapt e-commerce. This is in line with the previous studies in the context of e-commerce (e.g. Agag and El.Masry, 2016a).

The findings concerning the implications of website trustworthiness are in line with the conclusions of Teo and Liu (2007), Agag and El-Masry (2017) and Amaro and Duarte (2015). Additionally, they admit that citizens' intentions to use e-gov services is significantly and positively influenced by trustworthy links between the citizens and e-gov websites. Citizens' intentions to use e-gov services is found to has positive relations with compatibility and relative advantages. This result concurs the prior empirical findings e.g. (Kim and Lee, 2006; Ponte et al., 2015; Shareef et al., 2011).

The suggestion from the current study findings is that, to understand the link between perceived usefulness, Trust toward e-gov websites, relative advantages, and compatibility in e-gov context and intention to use e-gov services in technology acceptance, cultural background (uncertainty avoidance) as moderators play important role. Uncertainty avoidance significantly moderated this relation. Such finding demonstrates and advocates the view of Srite and Karahanna (2006) that personal behaviour is influenced by the social environment thought the powerful mechanism of culture. With respect to the influence of cultural background as a moderator toward the TAM constructs, consistence is existed in the results.

Furthermore, the fsQCA analysis shows that such a single variable is not sufficient to strengthen the higher intention to use e-gov services but that combinations of these factors are instead likely to do so. The results reveal that combinations of Trust toward government, trust toward technology, privacy/security, system quality, service quality, information quality, Trust toward websites, ease of use, relative advantages, and compatibility were found to be important precursors to citizens' intentions to use e-gov services.

\subsection{Managerial Implications}

The antecedent and consequences of individuals' trust towards e-gov websites, particularly in the context of developing country have been significantly overlooked by prior studies. Therefore, the current study was performed. As recognised by the current literature, demand for a powerful empirical 
investigation to analyse the precursors and the ramifications of individuals' trust toward e-gov websites was significantly required.

Practically, the current findings report various implications to the provisioners of online services and marketer in the management context. The results of the study will be very useful to the e-gov service providers as a tool to determine the e-gov continuance in "KSA". Several crucial implications for e-gov website managers and academic researchers, including the provision of a substantial contribution to the body of knowledge have been uncovered in several avenues.

First, the likelihood of adopting e-gov services is high when individuals perceived such innovation as relatively advantageous for them. It is suggested in the concept that when additional and beneficial extras are provided for e-gov, like convenience and quick service delivery with respect to precedent means, consequently, diffusion of such technology is going to take a place in society. Bearing in mind such important connotation, benefits of e-gov are crucial for citizens to imperatively be notified about by "KSA" government. Having knowledgeable citizens about e-gov services and its advantages play indispensable role to the adoption of such system. With the aim of insuring relative advantage, attentions are locally required to be directed toward initiatives and strategies in term of offering valuable services to consumers compared to precedent means of serving. Quickness and efficiency of the provided online services are significant elements in such context in term of operational development and reducing costs from a governmental standpoint, and more convenient from consumers' standpoint. Within the framework of trust, governmental decisions that are taken in regard of e-gov system and the ways its services are implemented should consider the involvement of local consumers by initiating proactive strategic plans and events. In such context, suggestions of providing localised community forums and implementing council's conferences can be utilised to the promotion of related debates and comprehensively understand e-gov by consumers. Particularly, promoting the consumers' awareness of e-gov system and its services by the complimentary ICT facilities of locally established libraries in "KSA" can be beneficial solution.

Second, it is beneficial form management standpoint to be knowledgeable about antecedents and consequences of consumers' trust and their effect on individuals' intentions to use e-gov services. This will help managers seeking to enhance consumers' trust toward government websites, thus, consumers' intention to use e-gov services by developing targeted strategical and actions plans. The present study has delivered empirically validated model that can support e-gov website managers in understanding the antecedents and consequences of trust toward e-gov websites. Trust toward technology, Trust toward government, privacy/security, propensity to trust, information quality, service quality, and system quality have appeared as fundamental factors to successfully form individuals' trust toward e-gov websites, hence increasing the intentions to use e-gov services. Accordingly, decisions can be made by management department to enhance information quality, system quality, service quality, propensity to trust, perceived privacy/security, Trust toward technology and Trust toward government. Perception of ease of use and perception of usefulness have also appeared as fundamental factors to successfully form individual trust toward e-gov websites, thus improving intentions to use e-gov services. Thus, decisions can be made by management department to enhance perception of ease of use and perception of usefulness. Government website managers can utilise technological advancement to support comfort and ease in promoting government services on the Internet. For example, e-gov website managers can provide applications for mobile devices to use e-gov services. Service quality was the first most influenced variable on consumers trust, which means, if the service providers provide good service quality such as availability and high reliability, the individual trust would be higher and that will increase individual intention to use e-gov services. Thereafter, the high system quality have a positive influence on individual trust as some factors like accessibility and availability which may hinder the usage and that consequently result in distrust and usage will be reduced. Information quality has the lower influence on trust among the other factors because the information quality would be based on accuracy and content quality which is depend on the service provided by the government. For instance, government can provide citizens with privacy protection mechanism, 
safe payment mechanism, and high transmission quality. Moreover, e-gov should encourage citizens to enter their personal information to utilize personalized and customized services.

Third, as perceived relative advantage significantly predicts individuals' intention to use e-gov services, e-gov website managers need to emphasise the advantages of using e-gov services on the Internet, considering the benefits that prospect consumers appreciate. The findings of this study have uncovered that monetary rewards are deemed prime advantages. Thus, e-gov website managers should guarantee lower prices and offer other monetary rewards such as discounts, coupons and other monetary rewards. Furthermore, discussion forums and chat rooms are other ways to enhance communication between the government and the citizens.

Finally, uncertainty avoidance influences the relationship between perceived usefulness, Trust toward websites, relative advantages, compatibility and citizens' intention to use e-gov services. The contribution and academic repercussions of this paper are that, while various researchers have used culture as a key variable in their studies, few of them have examined the moderating impact of cultural context on intention to use e-gov services, and even very few shine a spotlight on the government sector. Practitioners could perhaps recognise that current models are conditional in nature and thus serve only as a starting point for determining citizens' intentions to use e-gov services. To anticipate user acceptance of a particular system, one's cultural background should be taken into account.

\subsection{Theoretical Implications}

By extending the existing literature, the current study findings contribute to the knowledge of online trust by appraising the antecedents and the consequences of trust toward e-gov websites within emerging situation. The significance of these findings is based on the empirical testing of the selected theories that predominately established in the developed Western countries where strong, active and emerging marketplace is exist. Those markets are attractive for foreign marketers who are eager to access the market of "KSA". Accordingly, it theoretically implies that consumers' trust towards e-gov websites relies on nine main drivers:1) Trust toward government, 2) Trust toward technology, 3) privacy-security, 4) propensity to trust, 5) information quality, 6) system quality, 7) service quality, 8) relative advantages and 9) perception of ease of use. Moreover, the differences between consumers' Trust toward government, Trust toward technology, and Trust toward websites have not been sufficiently presented by preceding studies. In addition, the relations between them and the way that intention to use e-gov services is affected by them also have not been comprehensively understood. Thus, clearly differentiating between them from empirical as well as conceptional standpoints will give crucial and useful insights into the distinctive roles are played by them in the context of Internet. The results of the current study indicate that the relations between Perceptions of usefulness, Trust toward websites, relative advantages and citizens' intention to use e-gov services are conditioned by cultural background (uncertainty avoidance).

\subsection{Limitations and Further Potential Directions}

This research is bounded by specific limitations which give rich ground for new future ideas to be studied. Firstly, the selected variables to be tested and validated in this research have been studied at single point of time. Therefore, studying and analysing these variables longitudinally to help validating the suggested model will be a promising future idea to be researched. Secondly, despite the significant variance value is clarified by precursors of consumers' Trust toward e-gov websites, the inclusion of other crucial factors can be a chance for further study (e.g. customers' satisfaction with prior usage and their perception of sources reliability). Thirdly, there has been solid proof that establishing the link between individuals' intention and their real behaviour. Until now, in the context of e-gov, this link has been considerably disregarded. Further research should assert this link between intentions to use e-gov services and actual behaviour, since this relation has never been investigated in the e-gov context. Finally, the collection of the current study's data did not consider non-e-gov adopter as the attention was given to e-gov adopters with respect to their recent use of e-gov. Therefore, it could be a motivation idea to extend this study by testing its conceptual model with sample of non-e-gov adopter. 


\section{REFERENCES}

Adams, D. A., Nelson, R. R., \& Todd, P. A. (1992). Perceived Usefulness, Ease of Use, and Usage of Information Technology: A Replication. Management Information Systems Quarterly, 16(2), 227-247. doi:10.2307/249577

Agag, G., \& El-Masry, A. A. (2016a). Understanding consumer intention to participate in online travel community and effects on consumer intention to purchase travel online and WOM: An integration of innovation diffusion theory and TAM with trust. Computers in Human Behavior, 60, 97-111. doi:10.1016/j.chb.2016.02.038

Agag, G., \& El-Masry, A. A. (2016b). Understanding the determinants of hotel booking intentions and moderating role of habit. International Journal of Hospitality Management, 54, 52-67. doi:10.1016/j.ijhm.2016.01.007

Agag, G. M., \& El-Masry, A. A. (2017). Why Do Consumers Trust Online Travel Websites? Drivers and Outcomes of Consumer Trust toward Online Travel Websites. Journal of Travel Research, 56(3), 347-369. doi: $10.1177 / 0047287516643185$

Ahuja, M. K., \& Thatcher, J. B. (2005). Moving beyond intentions and toward the theory of trying: Effects of work environment and gender on post-adoption information technology use. Management Information Systems Quarterly, 29(3), 427-459. doi:10.2307/25148691

Akman, I., Yazici, A., Mishra, A., \& Arifoglu, A. (2005). E-Government: A global view and an empirical evaluation of some attributes of citizens. Government Information Quarterly, 22(2), 239-257. doi:10.1016/j. giq.2004.12.001

Al-Debei, M. M., Al-Lozi, E., \& Papazafeiropoulou, A. (2013). Why people keep coming back to Facebook: Explaining and predicting continuance participation from an extended theory of planned behaviour perspective. Decision Support Systems, 55(1), 43-54. doi:10.1016/j.dss.2012.12.032

Al-Hujran, O., Al-Debei, M. M., Chatfield, A., \& Migdadi, M. (2015). The imperative of influencing citizen attitude toward e-government adoption and use. Computers in Human Behavior, 53, 189-203. doi:10.1016/j. chb.2015.06.025

Al-Refaie, A., \& Ramadna, A. M. (2017). Barriers to E-Government Adoption in Jordanian Organizations from Users' and Employees' Perspectives. International Journal of Electronic Government Research, 13(1), 33-51. doi:10.4018/IJEGR.2017010103

Alomari, M., Woods, P., \& Sandhu, K. (2012). Predictors for e-government adoption in Jordan: Deployment of an empirical evaluation based on a citizen-centric approach. Information Technology \& People, 25(2), 207-234. doi:10.1108/09593841211232712

Aloudat, A., Michael, K., Chen, X., \& Al-Debei, M. M. (2014). Social acceptance of location-based mobile government services for emergency management. Telematics and Informatics, 31(1), 153-171. doi:10.1016/j. tele.2013.02.002

Alzahrani, L., Al-Karaghouli, W., \& Weerakkody, V. (2017). Analysing the critical factors influencing trust in e-government adoption from citizens' perspective: A systematic review and a conceptual framework. International Business Review, 26(1), 164-175. doi:10.1016/j.ibusrev.2016.06.004

Alzahrani, L., Al-Karaghouli, W., \& Weerakkody, V. (2018). Investigating the impact of citizens' trust toward the successful adoption of e-government: A multigroup analysis of gender, age, and internet experience. Information Systems Management, 35(2), 124-146. doi:10.1080/10580530.2018.1440730

Amaro, S., \& Duarte, P. (2015). An integrative model of consumers' intentions to purchase travel online. Tourism Management, 46, 64-79. doi:10.1016/j.tourman.2014.06.006

Anderson, J. C., \& Gerbing, D. W. (1988). Structural equation modeling in practice: A review and recommended two-step approach. Psychological Bulletin, 103(3), 411-423. doi:10.1037/0033-2909.103.3.411

Armstrong, J. S., \& Overton, T. S. (1977). Estimating nonresponse bias in mail surveys. JMR, Journal of Marketing Research, 14(3), 396-402. doi:10.1177/002224377701400320

Arslan, A. (2009). Cross-cultural analysis of European e-government adoption. Academic Press. 
Ashraf, A. R., Thongpapanl, N., \& Auh, S. (2014). The Application of the Technology Acceptance Model Under Different Cultural Contexts: The Case of Online Shopping Adoption. Journal of International Marketing, 22(3), 68-93. doi:10.1509/jim.14.0065

Ayeh, J. K. (2015). Travellers' acceptance of consumer-generated media: An integrated model of technology acceptance and source credibility theories. Computers in Human Behavior, 48, 173-180. doi:10.1016/j. chb.2014.12.049

Baron, R. M., \& Kenny, D. A. (1986). The moderator-mediator variable distinction in social psychological research: Conceptual, strategic, and statistical considerations. Journal of Personality and Social Psychology, 51(6), 1173-1182. doi:10.1037/0022-3514.51.6.1173 PMID:3806354

Bélanger, F., \& Carter, L. (2008). Trust and risk in e-government adoption. The Journal of Strategic Information Systems, 17(2), 165-176. doi:10.1016/j.jsis.2007.12.002

Beldad, A., van der Geest, T., de Jong, M., \& Steehouder, M. (2012). A cue or two and I'll trust you: Determinants of trust in government organizations in terms of their processing and usage of citizens' personal information disclosed online. Government Information Quarterly, 29(1), 41-49. doi:10.1016/j.giq.2011.05.003

Benbasat, I., Gefen, D., \& Pavlou, P. A. (2008). Special Issue: Trust in Online Environments. Journal of Management Information Systems, 24(4), 5-11. doi:10.2753/MIS0742-1222240400

Bhandari, M., \& Rodgers, S. (2018). What does the brand say? Effects of brand feedback to negative eWOM on brand trust and purchase intentions. International Journal of Advertising, 37(1), 125-141. doi:10.1080/02 650487.2017 .1349030

Bigné, E., Sanz, S., Ruiz, C., \& Aldás, J. 2010. Why Some Internet Users Don’t Buy Air Tickets Online, in: Gretzel, U., Law, R.,Fuchs, M. (Eds.), Information and Communication Technologies in Tourism 2010: Proceedings of the International Conference in Lugano, Switzerland, February 10-12, 2010. Springer Vienna. doi:10.1007/978-3-211-99407-8_18

Bradford, M., \& Florin, J. (2003). Examining the role of innovation diffusion factors on the implementation success of enterprise resource planning systems. International Journal of Accounting Information Systems, 4(3), 205-225. doi:10.1016/S1467-0895(03)00026-5

Cabanillas, L. F., Fernández, S. J., \& Leiva, M. F. (2014). Antecedents of the adoption of the new mobile payment systems: The moderating effect of age. Computers in Human Behavior, 35, 464-478. doi:10.1016/j. chb.2014.03.022

Carter, L., \& Bélanger, F. (2005). The utilization of e-government services: Citizen trust, innovation and acceptance factors*. Information Systems Journal, 15(1), 5-25. doi:10.1111/j.1365-2575.2005.00183.x

Castañeda, J. A., Leiva, M. F., \& Luque, T. (2007). Web Acceptance Model (WAM): Moderating effects of user experience. Information \& Management, 44(4), 384-396. doi:10.1016/j.im.2007.02.003

Chang, C. M., Hsu, M. H., Hsu, C. S., \& Cheng, H. L. (2014). Examining the role of perceived value in virtual communities continuance: Its antecedents and the influence of experience. Behaviour \& Information Technology, 33(5), 502-521. doi:10.1080/0144929X.2012.745607

Chen, J. V., Jubilado, R. J. M., Capistrano, E. P. S., \& Yen, D. C. (2015). Factors affecting online tax filing - An application of the IS Success Model and trust theory. Computers in Human Behavior, 43, 251-262. doi:10.1016/j. chb.2014.11.017

Chen, L., Gillenson, M. L., \& Sherrell, D. L. (2002). Enticing online consumers: An extended technology acceptance perspective. Information \& Management, 39(8), 705-719. doi:10.1016/S0378-7206(01)00127-6

Chin, W. W. (1998). The partial least squares approach for structural equation modeling, Modern methods for business research. Lawrence Erlbaum Associates Publishers.

Chin, W. W., Marcolin, B. L., \& Newsted, P. R. (2003). A partial least squares latent variable modeling approach for measuring interaction effects: Results from a Monte Carlo simulation study and an electronic-mail emotion/ adoption study. Information Systems Research, 14(2), 189-217. doi:10.1287/isre.14.2.189.16018 
Chinje, N., \& Chinomona, R. (2018). The Influence of Trust and Ease of Use of Social Media Platforms on South Africa's Generation Y Social Media Use Intention and Information Sharing. In G. Heggde \& G. Shainesh (Eds.), Social Media Marketing: Emerging Concepts and Applications (pp. 93-112). doi:10.1007/978-981-10-5323-8_7

Chiu, C. M., Hsu, M. H., Lai, H., \& Chang, C. M. (2012). Re-examining the influence of trust on online repeat purchase intention: The moderating role of habit and its antecedents. Decision Support Systems, 53(4), 835-845. doi:10.1016/j.dss.2012.05.021

Christou, E., \& Kassianidis, P. (2002). Consumer's Perceptions and Adoption of Online Buying for Travel Products. Journal of Travel \& Tourism Marketing, 12(4), 93-107. doi:10.1300/J073v12n04_06

Cohen, J. (1988). Statistical power analysis for the behavioral sciences. L. Erlbaum Associates.

Cronbach, L. J. (1970). Essentials of psychological testing. Harper and Row.

Davis, F. D. (1986). A technology acceptance model for empirically testing new end-user information systems: Theory and results. Massachusetts Institute of Technology.

Davis, F. D. (1989). Perceived Usefulness, Perceived Ease of Use, and User Acceptance of Information Technology. Management Information Systems Quarterly, 13(3), 319-340. doi:10.2307/249008

Davis, F. D., Bagozzi, R. P., \& Warshaw, P. R. (1989). User Acceptance of Computer Technology: A Comparison of Two Theoretical Models. Management Science, 35(8), 982-1003. doi:10.1287/mnsc.35.8.982

Dwivedi, Y. K., Shareef, M. A., Simintiras, A. C., Lal, B., \& Weerakkody, V. (2016). A generalised adoption model for services: A cross-country comparison of mobile health (m-health). Government Information Quarterly, 33(1), 174-187. doi:10.1016/j.giq.2015.06.003

Elbeltagi, I., \& Agag, G. (2016). E-retailing ethics and its impact on customer satisfaction and repurchase intention: A cultural and commitment-trust theory perspective. Internet Research, 26(1), 288-310. doi:10.1108/ IntR-10-2014-0244

Falk, R. F., \& Miller, N. B. (1992). A primer for soft modeling. University of Akron Press.

Fishbein, M., \& Ajzen, I. (1975). Belief, attitude, intention, and behavior: an introduction to theory and research. Addison-Wesley Pub. Co.

Fiss, P. C., Sharapov, D., \& Cronqvist, L. (2013). Opposites attract? Opportunities and challenges for integrating large-N QCA and econometric analysis. Political Research Quarterly, 66(1), 191-198.

Flavián, C., Guinalíu, M., \& Gurrea, R. (2006). The role played by perceived usability, satisfaction and consumer trust on website loyalty. Information \& Management, 43(1), 1-14. doi:10.1016/j.im.2005.01.002

Fornell, C., \& Larcker, D. F. (1981). Evaluating Structural Equation Models with Unobservable Variables and Measurement Error. JMR, Journal of Marketing Research, 18(1), 39-50. doi:10.1177/002224378101800104

Gary, M., Larry, N., Fazal, H. S., \& Benjamin, D. (2015). Investigating the factors influencing the adoption of m-banking: A cross cultural study. International Journal of Bank Marketing, 33(4), 545-570. doi:10.1108/ IJBM-07-2014-0100

Gefen, D. (2004). What Makes an ERP Implementation Relationship Worthwhile: Linking Trust Mechanisms and ERP Usefulness. Journal of Management Information Systems, 21(1), 263-288. doi:10.1080/07421222.2 004.11045792

Gefen, D., Karahanna, E., \& Straub, D. W. (2003). Trust and TAM in online shopping: An integrated model. Management Information Systems Quarterly, 27(1), 51-90. doi:10.2307/30036519

Gefen, D., \& Straub, D. W. (2000). The relative importance of perceived ease of use in IS adoption: A study of e-commerce adoption. Journal of the Association for Information Systems, 1(1), 8. doi:10.17705/1jais.00008

Gouscos, D., Kalikakis, M., Legal, M., \& Papadopoulou, S. (2007). A general model of performance and quality for one-stop e-Government service offerings. Government Information Quarterly, 24(4), 860-885. doi:10.1016/j. giq.2006.07.016

Grimmelikhuijsen, S., \& Knies, E. (2017). Validating a scale for citizen trust in government organizations. International Review of Administrative Sciences, 83(3), 583-601. doi:10.1177/0020852315585950 
Grimsley, M., \& Meehan, A. (2007). e-Government information systems: Evaluation-led design for public value and client trust. European Journal of Information Systems, 16(2), 134-148. doi:10.1057/palgrave.ejis.3000674

Hair, J. F. (2006). Multivariate Data Analysis (6th ed.). Pearson Prentice Hall.

Hair, J. F. (2013). A Primer on Partial Least Squares Structural Equation Modeling (PLS-SEM). SAGE Publications.

Hart, M., \& Porter, G. (2004). The Impact of Cognitive and other Factors on the Perceived Usefulness of OLAP. Journal of Computer Information Systems, 45, 47-56. doi:10.1080/08874417.2004.11645816

Heeks, R., \& Bailur, S. (2007). Analyzing e-government research: Perspectives, philosophies, theories, methods, and practice. Government Information Quarterly, 24(2), 243-265. doi:10.1016/j.giq.2006.06.005

Hibbing, J.R., \& Theiss, M.E. (2001). Introduction: Studying the American people's attitudes toward government. What is it about government that Americans dislike, 1-7.

Hofstede, G. (1980). Culture's consequences. Sage.

Hofstede, G. (2011). Dimensionalizing cultures: The Hofstede model in context. Online Readings in Psychology and Culture, 2(1), 8. doi:10.9707/2307-0919.1014

Hofstede, G., Hofstede, G. J., \& Minkov, M. (2010). Cultures and Organizations: Software of the Mind (3rd ed.). McGraw-Hill Education.

Hofstede, G. H. (2001). Culture's consequences: comparing values, behaviors, institutions, and organizations across nations. Sage Publications.

Hsu, M. H., Chang, C. M., Chu, K. K., \& Lee, Y. J. (2014). Determinants of repurchase intention in online groupbuying: The perspectives of DeLone \& McLean IS success model and trust. Computers in Human Behavior, 36, 234-245. doi:10.1016/j.chb.2014.03.065

Hung, S. Y., Chang, C. M., \& Yu, T. J. (2006). Determinants of user acceptance of the e-Government services: The case of online tax filing and payment system. Government Information Quarterly, 23(1), 97-122. doi:10.1016/j. giq.2005.11.005

Ifeonu, R.O., \& Ward, R. (2017). Towards A Comprehensive Framework For Measuring Technology Trust: The Case Of Mobile Banking Adoption In Nigeria. International Journal of Computer and Information Technology, 6.

Im, I., Hong, S., \& Kang, M. S. (2011). An international comparison of technology adoption: Testing the UTAUT model. Information \& Management, 48(1), 1-8. doi:10.1016/j.im.2010.09.001

Jafari, S. M., Ali, N. A., Sambasivan, M., \& Said, M. F. (2011). A respecification and extension of DeLone and McLean model of IS success in the citizen-centric e-governance. Paper presented at the 2011 IEEE International Conference on Information Reuse \& Integration. doi:10.1109/IRI.2011.6009571

Jörg, H., Christian, M. R., \& Marko, S. (2012). Using Partial Least Squares Path Modeling in Advertising Research: Basic Concepts and Recent Issues. Edward Elgar Publishing, Inc.

Karkin, N., \& Janssen, M. (2014). Evaluating websites from a public value perspective: A review of Turkish local government websites. International Journal of Information Management, 34(3), 351-363. doi:10.1016/j. ijinfomgt.2013.11.004

Kim, D. J., Ferrin, D. L., \& Rao, H. R. (2008). A trust-based consumer decision-making model in electronic commerce: The role of trust, perceived risk, and their antecedents. Decision Support Systems, 44(2), 544-564. doi:10.1016/j.dss.2007.07.001

Kim, L. H., Kim, D. J., \& Leong, J. K. (2005). The Effect of Perceived Risk on Purchase Intention in Purchasing Airline Tickets Online. Journal of Hospitality \& Leisure Marketing, 13(2), 33-53. doi:10.1300/J150v13n02_04

Kim, M. J., Chung, N., \& Lee, C. K. (2011). The effect of perceived trust on electronic commerce: Shopping online for tourism products and services in South Korea. Tourism Management, 32(2), 256-265. doi:10.1016/j. tourman.2010.01.011

Kim, S., \& Lee, Y. (2006). Global online marketplace: A cross-cultural comparison of website quality. International Journal of Consumer Studies, 30(6), 533-543. doi:10.1111/j.1470-6431.2006.00522.x 
Kurfalı, M., Arifoğlu, A., Tokdemir, G., \& Paçin, Y. (2017). Adoption of e-government services in Turkey. Computers in Human Behavior, 66, 168-178. doi:10.1016/j.chb.2016.09.041

Lam, T., Cho, V., \& Qu, H. (2007). A study of hotel employee behavioral intentions towards adoption of information technology. International Journal of Hospitality Management, 26(1), 49-65. doi:10.1016/j. ijhm.2005.09.002

Lee, J., Kim, H. J., \& Ahn, M. J. (2011a). The willingness of e-Government service adoption by business users: The role of offline service quality and trust in technology. Government Information Quarterly, 28(2), 222-230. doi:10.1016/j.giq.2010.07.007

Lee, M. K. O., \& Turban, E. (2001). A Trust Model for Consumer Internet Shopping. International Journal of Electronic Commerce, 6(1), 75-91. doi:10.1080/10864415.2001.11044227

Lee, S.-G., Trimi, S., \& Kim, C. (2013). The impact of cultural differences on technology adoption. Journal of World Business, 48(1), 20-29. doi:10.1016/j.jwb.2012.06.003

Lee, Y.-H., Hsieh, Y.-C., \& Hsu, C.-N. (2011b). Adding innovation diffusion theory to the technology acceptance model: Supporting employees' intentions to use e-learning systems. Journal of Educational Technology \& Society, 14, 124.

Li, X., Hess, T. J., McNab, A. L., \& Yu, Y. (2009). Culture and acceptance of global web sites: A cross-country study of the effects of national cultural values on acceptance of a personal web portal. SIGMIS Database, 40(4), 49-74. doi:10.1145/1644953.1644959

Lin, F., Fofanah, S. S., \& Liang, D. (2011). Assessing citizen adoption of e-Government initiatives in Gambia: A validation of the technology acceptance model in information systems success. Government Information Quarterly, 28(2), 271-279. doi:10.1016/j.giq.2010.09.004

Liu, Y., Li, H., Kostakos, V., Goncalves, J., Hosio, S., \& Hu, F. (2014). An empirical investigation of mobile government adoption in rural China: A case study in Zhejiang province. Government Information Quarterly, 31(3), 432-442. doi:10.1016/j.giq.2014.02.008

López, N. C., Molina, C. F. J., \& Bouwman, H. (2008). An assessment of advanced mobile services acceptance: Contributions from TAM and diffusion theory models. Information \& Management, 45(6), 359-364. doi:10.1016/j.im.2008.05.001

Magnusson, P., Westjohn, S. A., Semenov, A. V., Randrianasolo, A. A., \& Zdravkovic, S. (2013). The Role of Cultural Intelligence in Marketing Adaptation and Export Performance. Journal of International Marketing, 21(4), 44-61. doi:10.1509/jim.13.0055

Mansoori, K. A. A., Sarabdeen, J., \& Tchantchane, A. L. (2018). Investigating Emirati citizens' adoption of e-government services in Abu Dhabi using modified UTAUT model. Information Technology \& People, 31(2), 455-481. doi:10.1108/ITP-12-2016-0290

McCoy, S., Galletta, D. F., \& King, W. R. (2005). Integrating national culture into IS research: The need for current individual level measures. Communications of the Association for Information Systems, 15, 12. doi:10.17705/1CAIS.01512

McCoy, S., Galletta, D. F., \& King, W. R. (2007). Applying TAM across cultures: The need for caution. European Journal of Information Systems, 16(1), 81-90. doi:10.1057/palgrave.ejis.3000659

McKnight, D. H., \& Chervany, N. L. (2001). What Trust Means in E-Commerce Customer Relationships: An Interdisciplinary Conceptual Typology. International Journal of Electronic Commerce, 6(2), 35-59. doi:10.10 80/10864415.2001.11044235

McKnight, D. H., Choudhury, V., \& Kacmar, C. (2002). The impact of initial consumer trust on intentions to transact with a web site: A trust building model. The Journal of Strategic Information Systems, 11(3-4), 297-323. doi:10.1016/S0963-8687(02)00020-3

Moital, M., Vaughan, R., \& Edwards, J. (2009). Using involvement for segmenting the adoption of e-commerce in travel. Service Industries Journal, 29(5), 723-739. doi:10.1080/02642060902720253

Moore, G. C., \& Benbasat, I. (1991). Development of an Instrument to Measure the Perceptions of Adopting an Information Technology Innovation. Information Systems Research, 2(3), 192-222. doi:10.1287/isre.2.3.192 
Morosan, C. (2012). Theoretical and Empirical Considerations of Guests' Perceptions of Biometric Systems in Hotels. Journal of Hospitality \& Tourism Research (Washington, D.C.), 36(1), 52-84. doi:10.1177/1096348010380601

Nam, T. (2018). Examining the anti-corruption effect of e-government and the moderating effect of national culture: A cross-country study. Government Information Quarterly, 35(2), 273-282. Advance online publication. doi:10.1016/j.giq.2018.01.005

Pappas, N., \& Papatheodorou, A. (2017). Tourism and the refugee crisis in Greece: Perceptions and decisionmaking of accommodation providers. Tourism Management, 63(2), 31-41. doi:10.1016/j.tourman.2017.06.005

Park, S. Y. (2009). An Analysis of the Technology Acceptance Model in Understanding University Students' Behavioral Intention to Use e-Learning. Journal of Educational Technology \& Society, 12, 150-162.

Paul, S., \& Roi, C. (2018). The Role of Trust in an Information Technology Milieu: An Overview. Canadian Journal of Applied Science and Technology, 5.

Pavlou, P. A. (2003). Consumer Acceptance of Electronic Commerce: Integrating Trust and Risk with the Technology Acceptance Model. International Journal of Electronic Commerce, 7(3), 101-134. doi:10.1080/1 0864415.2003.11044275

Podsakoff, P. M., \& Organ, D. W. (1986). Self-reports in organizational research: Problems and prospects. Journal of Management, 12(4), 531-544. doi:10.1177/014920638601200408

Ragin, C. C., \& Davey, S. (2014). Fuzzy-set/Qualitative Comparative Analysis 2.5. Department of Sociology, University of California.

Rana, N. P., \& Dwivedi, Y. K. (2015). Citizen's adoption of an e-government system: Validating extended social cognitive theory (SCT). Government Information Quarterly, 32(2), 172-181. doi:10.1016/j.giq.2015.02.002

Rana, N. P., Dwivedi, Y. K., Williams, M. D., \& Weerakkody, V. (2016). Adoption of online public grievance redressal system in India: Toward developing a unified view. Computers in Human Behavior, 59, 265-282. doi:10.1016/j.chb.2016.02.019

Ravishankar, M. N. (2013). Public ICT innovations: A strategic ambiguity perspective. Journal of Information Technology, 28(4), 316-332. doi:10.1057/jit.2013.18

Reddick, C. G., \& Roy, J. (2013). Business perceptions and satisfaction with e-government: Findings from a Canadian survey. Government Information Quarterly, 30(1), 1-9. doi:10.1016/j.giq.2012.06.009

Rodríguez, T. E., \& Trujillo, E. C. (2014). Online purchasing tickets for low cost carriers: An application of the unified theory of acceptance and use of technology (UTAUT) model. Tourism Management, 43, 70-88. doi:10.1016/j.tourman.2014.01.017

Rogers, E. M. (1962). Diffusion of innovations. Free Press.

Rogers, E. M. (1995). Diffusion of innovations. Free Press.

Rogers, E. M. (2003). Diffusion of Innovations (5th ed.). Free Press.

Rogers, E. M. (2010). Diffusion of Innovations (4th ed.). Free Press.

Roman, S. (2007). The Ethics of Online Retailing: A Scale Development and Validation from the Consumers' Perspective. Journal of Business Ethics, 72(2), 131-148. doi:10.1007/s10551-006-9161-y

Rotter, J. B. (1967). A new scale for the measurement of interpersonal trust1. Journal of Personality, 35(4), 651-665. doi:10.1111/j.1467-6494.1967.tb01454.x PMID:4865583

Sabiote, C. M., Frías, D. M., \& Castañeda, J. A. (2012). E-service quality as antecedent to e-satisfaction: The moderating effect of culture. Online Information Review, 36(2), 157-174. doi:10.1108/14684521211229011

Schaupp, L. C., Carter, L., \& McBride, M. E. (2010). E-file adoption: A study of U.S. taxpayers' intentions. Computers in Human Behavior, 26(4), 636-644. doi:10.1016/j.chb.2009.12.017

Sekaran, U. (2003). Research Methods for Business: A Skill-building Approach. Wiley. 
Seng, W. M., Jackson, S., \& Philip, G. (2010). Cultural issues in developing E-Government in Malaysia. Behaviour \& Information Technology, 29(4), 423-432. doi:10.1080/01449290903300931

Shareef, M. A., Dwivedi, Y. K., Kumar, V., \& Kumar, U. (2016). Reformation of public service to meet citizens' needs as customers: Evaluating SMS as an alternative service delivery channel. Computers in Human Behavior, 61, 255-270. doi:10.1016/j.chb.2016.03.002

Shareef, M. A., Kumar, V., Kumar, U., \& Dwivedi, Y. K. (2011). e-Government Adoption Model (GAM): Differing service maturity levels. Government Information Quarterly, 28(1), 17-35. doi:10.1016/j.giq.2010.05.006

Shih, H. P. (2004). An empirical study on predicting user acceptance of e-shopping on the Web. Information \& Management, 41(3), 351-368. doi:10.1016/S0378-7206(03)00079-X

Shin, D. H. (2010). MVNO services: Policy implications for promoting MVNO diffusion. Telecommunications Policy, 34(10), 616-632. doi:10.1016/j.telpol.2010.07.001

Sigala, M., Airey, D., Jones, P., \& Lockwood, A. (2000). The Diffusion And Application Of Multimedia Technologies In The Tourism And Hospitality Industries, Vienna. Academic Press.

Sirdeshmukh, D., Singh, J., \& Sabol, B. (2002). Consumer Trust, Value, and Loyalty in Relational Exchanges. Journal of Marketing, 66(1), 15-37. doi:10.1509/jmkg.66.1.15.18449

Slyke, C. V., Belanger, F., \& Comunale, C. L. (2004). Factors influencing the adoption of web-based shopping: The impact of trust. SIGMIS Database, 35(2), 32-49. doi:10.1145/1007965.1007969

Srite, M., \& Karahanna, E. (2006). The role of espoused national cultural values in technology acceptance. Management Information Systems Quarterly, 30(3), 679-704. doi:10.2307/25148745

Srivastava, S. C., \& Teo, T. S. (2009). Citizen trust development for e-government adoption and usage: Insights from young adults in Singapore. Communications of the Association for Information Systems, $25,31$. doi:10.17705/1CAIS.02531

Takieddine, S., \& Sun, J. (2015). Internet banking diffusion: A country-level analysis. Electronic Commerce Research and Applications, 14(5), 361-371. doi:10.1016/j.elerap.2015.06.001

Tam, C., \& Oliveira, T. (2017). Understanding mobile banking individual performance: The DeLone \& McLean model and the moderating effects of individual culture. Internet Research, 27(3), 538-562. doi:10.1108/IntR05-2016-0117

Tarhini, A., Hone, K., Liu, X., \& Tarhini, T. (2017). Examining the moderating effect of individual-level cultural values on users' acceptance of E-learning in developing countries: A structural equation modeling of an extended technology acceptance model. Interactive Learning Environments, 25(3), 306-328. doi:10.1080/ 10494820.2015 .1122635

Taylor, S., \& Todd, P. (1995). Assessing IT usage: The role of prior experience. Management Information Systems Quarterly, 19(4), 561-570. doi:10.2307/249633

Teo, T. S. H., \& Liu, J. (2007). Consumer trust in e-commerce in the United States, Singapore and China. Omega, 35(1), 22-38. doi:10.1016/j.omega.2005.02.001

Teo, T. S. H., Srivastava, S. C., \& Jiang, L. (2008). Trust and Electronic Government Success: An Empirical Study. Journal of Management Information Systems, 25(3), 99-131. doi:10.2753/MIS0742-1222250303

Tsaur, S. H., Lin, C. T., \& Wu, C. S. (2005). Cultural Differences of Service Quality and Behavioral Intention in Tourist Hotels. Journal of Hospitality \& Leisure Marketing, 13(1), 41-63. doi:10.1300/J150v13n01_04

Tung, F. C., Chang, S. C., \& Chou, C. M. (2008). An extension of trust and TAM model with IDT in the adoption of the electronic logistics information system in HIS in the medical industry. International Journal of Medical Informatics, 77(5), 324-335. doi:10.1016/j.ijmedinf.2007.06.006 PMID:17644029

United Nations. (2015). World Population Prospects: The 2015 Revision. Population Division. Available at: https://esa.un.org/unpd/wpp/publications/

Urbach, N., Smolnik, S., \& Riempp, G. (2010). An empirical investigation of employee portal success. The Journal of Strategic Information Systems, 19(3), 184-206. doi:10.1016/j.jsis.2010.06.002 
Veeramootoo, N., Nunkoo, R., \& Dwivedi, Y. K. (2018). What determines success of an e-government service? Validation of an integrative model of e-filing continuance usage. Government Information Quarterly, 35(2), 161-174. Advance online publication. doi:10.1016/j.giq.2018.03.004

Venkatesh, V., \& Davis, F. D. (2000). A Theoretical Extension of the Technology Acceptance Model: Four Longitudinal Field Studies. Management Science, 46(2), 186-204. doi:10.1287/mnsc.46.2.186.11926

Venkatesh, V., Morris, M. G., Davis, G. B., \& Davis, F. D. (2003). User Acceptance of Information Technology: Toward a Unified View. Management Information Systems Quarterly, 27(3), 425-478. doi:10.2307/30036540

Wang, W., \& Benbasat, I. (2008). Attributions of Trust in Decision Support Technologies: A Study of Recommendation Agents for E-Commerce. Journal of Management Information Systems, 24(4), 249-273. doi:10.2753/MIS0742-1222240410

Wang, X., Yuen, K. F., Wong, Y. D., \& Teo, C. C. (2018). An innovation diffusion perspective of e-consumers' initial adoption of self-collection service via automated parcel station. International Journal of Logistics Management, 29(1), 237-260. doi:10.1108/IJLM-12-2016-0302

Warkentin, M., Sharma, S., Gefen, D., Rose, G. M., \& Pavlou, P. (2018). Social identity and trust in internetbased voting adoption. Government Information Quarterly, 35(2), 195-209. Advance online publication. doi:10.1016/j.giq.2018.03.007

Weerakkody, V., El-Haddadeh, R., Al-Sobhi, F., Shareef, M. A., \& Dwivedi, Y. K. (2013). Examining the influence of intermediaries in facilitating e-government adoption: An empirical investigation. International Journal of Information Management, 33(5), 716-725. doi:10.1016/j.ijinfomgt.2013.05.001

Wong, J., \& Law, R. (2005). Analysing the intention to purchase on hotel websites: A study of travellers to Hong Kong. International Journal of Hospitality Management, 24(3), 311-329. doi:10.1016/j.jhm.2004.08.002

Wu, J.-H., \& Wang, S.-C. (2005). What drives mobile commerce?: An empirical evaluation of the revised technology acceptance model. Information \& Management, 42(5), 719-729. doi:10.1016/j.im.2004.07.001

Yen, Y. Y. HP, Y.P., \& Nena, L. (2015). Internet banking acceptance in the United States and Malaysia: a crosscultural examination. Marketing Intelligence \& Planning, 33, 292-308. doi: doi:10.1108/MIP-08-2013-0126

Yeniyurt, S., \& Townsend, J. D. (2003). Does culture explain acceptance of new products in a country?: An empirical investigation. International Marketing Review, 20(4), 377-396. doi:10.1108/02651330310485153

YESSER. (2006). The e-Government First Action Plan (2006 and 2010). Saudi Ministry of Communication and Information Technology. Available at: https://www.yesser.gov.sa/en/MechanismsandRegulations/Documents/ National_E-Gov_Action_Plan_(F).pdf

YESSER. (2016). The e-Government Second Action Plan (2012 and 2016). Saudi Ministry of Communication and Information Technology. Available at: https://www.yesser.gov.sa/EN/MechanismsandRegulations/strategy/ Documents/the_2nd_egovernment_action_plan_ENG.pdf 